\title{
Lightweight Aggregate as Internal Curing Agent to Limit Concrete Shrinkage
}

\author{
by JoAnn Browning, David Darwin, Diane Reynolds, and Benjamin Pendergrass
}

\begin{abstract}
The effectiveness of prewetted, vacuum-saturated (PVS) lightweight aggregate (LWA) as an internal curing agent to reduce concrete shrinkage is evaluated for curing periods of 7 and 14 days. Normalweight aggregate is replaced by LWA at volume replacement levels ranging from 8.9 to $13.8 \%$. Some mixtures contain a partial replacement of portland cement with slag cement while maintaining the paste content at approximately $24.1 \%$ of concrete volume. Comparisons are made with mixtures containing low-absorption granite and high-absorption limestone normalweight coarse aggregates. At the replacement levels used in this study, PVS LWA results in a small reduction in concrete density, no appreciable effect on concrete compressive strength, and a substantial decrease in concrete shrinkage for drying periods up to 365 days. Increasing the curing period from 7 to 14 days reduces concrete shrinkage. Thirty and $60 \%$ volume replacements of portland cement by slag cement result in reduced shrinkage when used with a porous LWA or normalweight aggregate. After 30 and 365 days of drying, all mixtures with LWA exhibited less shrinkage than the mixtures with either low-or high-absorption normalweight aggregates.
\end{abstract}

Keywords: bridge decks; cracking; curing; drying shrinkage; lightweight aggregate; slag cement; vacuum saturation.

\section{INTRODUCTION}

Drying shrinkage is a principal cause of cracking in concrete structures. For a wide variety of structures, however, the cracking can be accommodated (such as with joints in slabs-on-ground) or modified (such as through minimum reinforcement in structural slabs) so that the performance of the overall structure is not affected. One significant case where this is not true is bridge decks, where drying shrinkage cracking combines with plastic shrinkage, settlement, and thermal cracking to lower the durability of the decks by allowing water and deicing chemicals to penetrate the concrete and increase the susceptibility of the reinforcing steel to corrosion. ${ }^{1-3}$

A key aspect of work underway at the University of Kansas to minimize cracking in bridge decks is to develop concrete mixtures that will minimize concrete shrinkage. It is well established that the lower restraint provided by lightweight aggregates (LWAs) can lead to increased drying shrinkage compared with mixtures containing normalweight aggregates, ${ }^{4}$ and if not adequately prewetted, the unsaturated pores lead to greater water demand during construction and result in inadequate water for hydration. Because of the absorption and desorption properties of the aggregate, ${ }^{5}$ however, vacuum-saturated LWAs can readily provide an internal source of water to increase hydration and lessen the drying effects on a concrete mixture. Efforts to reduce autogenous shrinkage in concretes with low watercementitious material ratios $(w / \mathrm{cm})$, first suggested by Philleo, ${ }^{6}$ have demonstrated the success of using a partial replacement of normalweight aggregate with prewetted, vacuum-saturated (PVS) LWA. ${ }^{7-11}$ Autogenous shrinkage, however, is not a concern at the $w / \mathrm{cm}$ used in bridge decks, which are typically greater than 0.42 .

Research using porous normalweight aggregates in combination with slag cement as a partial replacement for portland cement has demonstrated that the combination can significantly reduce shrinkage compared to concretes containing porous normalweight aggregate without slag or nonporous normalweight aggregate with slag. ${ }^{2-15}$

In this study of concretes with a $w / \mathrm{cm}$ typical of that used in bridge decks and at which autogenous shrinkage should not occur, the use of PVS LWA as a partial replacement for normalweight aggregate is investigated to determine its effectiveness at reducing shrinkage both with and without slag cement. Control mixtures without LWA containing normalweight coarse aggregates with both low and high absorptions are also tested.

Powers ${ }^{16}$ observed that the length of curing has little effect on concrete shrinkage. His work was based, however, on cements that were not ground as finely as those currently in use. The effect of an increased curing period on drying shrinkage is included in this study.

\section{RESEARCH SIGNIFICANCE}

This study demonstrates that a partial replacement of normalweight aggregate with PVS LWA will reduce drying shrinkage and that the effectiveness of the LWA is enhanced through the use of slag cement. This study also demonstrates the positive impact of extended curing on reducing shrinkage. Taken together, the results provide the basis for a combined strategy to reduce drying shrinkageand by extension, the cracking that accompanies it-in reinforced concrete bridge decks.

\section{Materials}

\section{EXPERIMENTAL INVESTIGATION}

The concretes in this study contained Type I/II portland cement, river-run sand and pea gravel, 3/4 in. (19 mm) maximum-size crushed granite (with an absorption of 0.71 to $0.76 \%$ ) or limestone (with an absorption of $3.07 \%$ ) coarse aggregate, a polycarboxylate-based high-range waterreducing admixture (HRWRA), and a tall oil (liquid rosin)based air-entraining agent. The LWA was expanded shale. Because the concrete is intended for use in low-cracking mixtures with low paste contents, an intermediate-sized

ACI Materials Journal, V. 108, No. 6, November-December 2011

MS No. M-2010-359 received November 12, 2010, and reviewed under Institute publication policies. Copyright (c) 2011, American Concrete Institute. All rights reserved, including the making of copies unless permission is obtained from the copyright proprietors. Pertinent discussion including author's closure, if any, will be published in the September-October 2012 ACI Materials Journal if the discussion is received by June 1, 2012. 
$\overline{\text { JoAnn Browning, FACI, is a Professor of Civil, Environmental and Architectural }}$ Engineering at the University of Kansas, Lawrence, KS. She is Chair of ACI Committee 314, Simplified Design of Concrete Buildings, and is a member of ACI Committees 318 , Structural Concrete Building Code; 341, Earthquake-Resistant Concrete Bridges; and 374, Performance-Based Seismic Design of Concrete Buildings, and Joint ACI-ASCE Committee 408, Development and Splicing of Deformed Bars.

David Darwin, FACI, is the Deane E. Ackers Distinguished Professor of Civil, Environmental and Architectural Engineering and Director of the Structural Engineering and Materials Laboratory at the University of Kansas. He is a member of ACI Committees 130, Sustainability of Concrete; 222, Corrosion of Metals in Concrete; 224, Cracking; and 318, Structural Concrete Building Code, and Joint ACI-ASCE Committees 408, Development and Splicing of Deformed Bars; 445, Shear and Torsion; and 446, Fracture Mechanics of Concrete.

Diane Reynolds is an Engineer at BG Consultants, Lawrence, KS. She received her $B S$ in architectural engineering and her $M S$ in civil engineering from the University of Kansas.

ACI member Benjamin Pendergrass is a Graduate Teaching and Research Assistant at the University of Kansas. He received his BA in physics from Drury University, Springfield, $M O$, and his $B S$ in civil and environmental engineering from the University of Missouri, Columbia, Columbia, $\mathrm{MO}$

(rather than fine) aggregate gradation (97\% of particles pass the $3 / 8 \mathrm{in}$. [9.5 $\mathrm{mm}$ ] sieve and are retained on the No. 16 [1.18 mm] sieve) was selected for ease of handling and placing during bridge deck construction and ease of handling in the laboratory. Some mixtures contained Grade 100 slag cement as a partial replacement for portland cement.

The LWA was prewetted using a vacuum saturation process and used in a nominally surface-dry condition (PVS-SD). The river sand and pea gravel were batched in a wet condition, with appropriate corrections to the mixture water, and the normalweight coarse aggregates were batched in a saturated surface-dry (SSD) condition. The aggregate properties and mixture proportions are summarized in the concrete mixtures section.
Two Type I/II portland cements were used. The cement used for Program I (described in the following) had a specific gravity of 3.20 and a Blaine fineness of $384 \mathrm{~m}^{2} / \mathrm{kg}$ (1875 $\mathrm{ft}^{2} / \mathrm{lb}$ ), while the cement used for Program II had a specific gravity of 3.15 and a Blaine fineness of $339 \mathrm{~m}^{2} / \mathrm{kg}$ $\left(1655 \mathrm{ft}^{2} / \mathrm{lb}\right)$. The Grade 100 slag cement had a specific gravity of 2.86 .

Further details on the material properties are presented in Reference 17.

\section{Vacuum saturation}

To provide water for internal curing, the LWAs were prewetted at a vacuum of 5.9 psi $(0.041 \mathrm{MPa})$ for 1 hour. After vacuum saturation, the intermediate-sized LWA was prepared to a PVS-SD condition by drying it with cloth towels. The nominal specific gravity of the LWA (specific gravity factor) - 1.54 - was found using a pycnometer. ${ }^{18}$ The water absorbed by the LWA ranged from 24.7 to $30.0 \%$ based on the dry weight of the aggregate.

\section{Concrete mixtures}

The mixtures used in this study were based on low-shrinkage mixtures with low cement paste contents and optimized aggregate gradations that are currently in use in the field. ${ }^{15,19}$ This study involved two programs, summarized in Table 1, which shows the concrete mixture proportions, the total water in all the aggregates, and the paste content as a percentage of concrete volume. The water in the aggregates represents the water held within the aggregate pores at the time of batching — water that is available to aid internal curing while not affecting the $w / \mathrm{cm}$. The aggregates in the granite coarse control mixtures contained approximately $19 \mathrm{lb} / \mathrm{yd}^{3}$ $\left(11 \mathrm{~kg} / \mathrm{m}^{3}\right)$ of water. The aggregates in the other mixtures contained considerably more water- $45 \mathrm{lb} / \mathrm{yd}^{3}\left(26.7 \mathrm{~kg} / \mathrm{m}^{3}\right)$ for the mixtures containing a limestone coarse aggregate

Table 1-Mixture proportions, $\mathrm{lb} / \mathrm{yd}^{3}$

\begin{tabular}{|c|c|c|c|c|c|c|c|c|c|}
\hline Mixture & Cement & Slag & Water & Sand* & Pea gravel ${ }^{\dagger}$ & LWA & Coarse aggregate & Water in aggregate & Paste percentage by volume \\
\hline Granite coarse aggregate-control & 540 & - & 238 & 1074 & 685 & - & $1226^{\ddagger}$ & 19 & 24.10 \\
\hline Limestone coarse aggregate-control & 540 & - & 238 & 1241 & 522 & - & $1215^{\S}$ & 45 & 24.10 \\
\hline LWA-low replacement & 540 & - & 238 & 1074 & 433 & $148 \|$ & $1226^{\#}$ & 46 & 24.10 \\
\hline LWA-medium replacement & 540 & - & 238 & 1057 & 305 & $199^{* *}$ & $1285^{\#}$ & 55 & 24.10 \\
\hline \multicolumn{10}{|c|}{ Program II } \\
\hline Granite coarse aggregate-control & 540 & - & 238 & 925 & 812 & - & $1239^{\#}$ & 19 & 24.29 \\
\hline LWA-30\% slag & 384 & 149 & 235 & 923 & 564 & $195^{\text {糔 }}$ & $1243^{\#}$ & 62 & 24.18 \\
\hline LWA- $60 \%$ slag & 226 & 303 & 233 & 933 & 617 & $195^{\S \S}$ & $1178^{\#}$ & 58 & 24.26 \\
\hline
\end{tabular}

*Bulk specific gravity (SSD) is 2.62; absorption (dry) is $0.33 \%$.

Bulk specific gravity (SSD) is 2.61; absorption (dry) is $0.93 \%$

${ }^{*}$ Granite; bulk specific gravity (SSD) is 2.60 ; absorption (dry) is $0.76 \%$

${ }^{\S}$ Limestone; bulk specific gravity (SSD) is 2.59 ; absorption (dry) is $3.07 \%$.

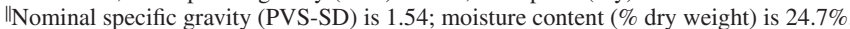

${ }^{\#}$ Granite; bulk specific gravity (SSD) is 2.60 ; absorption (dry) is $0.71 \%$.

${ }^{* *}$ Nominal specific gravity (PVS-SD) is 1.54 ; moisture content (\% dry weight) is $25.2 \%$.

${ }^{\dagger}$ Nominal specific gravity (PVS-SD) is 1.54 ; moisture content ( $\%$ dry weight) is $29.5 \%$.

* Nominal specific gravity (PVS-SD) is 1.54 ; moisture content (\% dry weight) is $30.0 \%$.

${ }^{\S}$ Nominal specific gravity (PVS-SD) is 1.54 ; moisture content (\% dry weight) is $26.5 \%$.

Notes: $1 \mathrm{lb} / \mathrm{yd}^{3}=0.5933 \mathrm{~kg} / \mathrm{m}^{3} ; w / c=0.44$ for Program I and $w / \mathrm{cm}=0.44$ for Program II 


\begin{tabular}{|c|c|c|c|c|c|c|}
\hline Mixture & Slump, in. $(\mathrm{mm})$ & Air content, $\%$ & $\begin{array}{c}\text { Temperature at } \\
\text { batching, }{ }^{\circ} \mathrm{F}\left({ }^{\circ} \mathrm{C}\right)\end{array}$ & $\begin{array}{c}\text { Unit weight, } \mathrm{lb} / \mathrm{ft}^{3} \\
\left(\mathrm{~kg} / \mathrm{m}^{3}\right)\end{array}$ & $\begin{array}{l}\text { 7-day compressive } \\
\text { strength, psi (MPa) }\end{array}$ & $\begin{array}{l}\text { 28-day compressive } \\
\text { strength, psi (MPa) }\end{array}$ \\
\hline \multicolumn{7}{|c|}{ Program I } \\
\hline Limestone coarse aggregate-control & $4(100)$ & 8.65 & $72(22)$ & $139.2(2230)$ & $3260(22.5)$ & $4460(30.8)$ \\
\hline LWA-low replacement & $2(50)$ & 8.40 & $70(21)$ & $133.9(2145)$ & $3640(25.1)$ & $4450(30.7)$ \\
\hline LWA-high replacement & $3.25(85)$ & 8.15 & $69(21)$ & $130.5(2091)$ & $3950(27.2)$ & $4850(33.4)$ \\
\hline \multicolumn{7}{|c|}{ Program II } \\
\hline Granite coarse aggregate-control & $3.5(90)$ & 8.90 & $72(22)$ & $139.0(2227)$ & $2950(20.3)$ & $4140(28.5)$ \\
\hline LWA-30\% slag & $3.75(95)$ & 8.15 & $74(23)$ & $135.3(2168)$ & $3240(22.3)$ & $4950(34.1)$ \\
\hline Limestone coarse aggregate- $60 \%$ slag & $4(100)$ & 8.65 & $73(23)$ & $138.3(2215)$ & $2730(18.8)$ & $4570(31.5)$ \\
\hline
\end{tabular}

and between 46 and $70 \mathrm{lb} / \mathrm{yd}^{3}\left(27.3\right.$ and $41.5 \mathrm{~kg} / \mathrm{m}^{3}$ ) for the mixtures containing a partial replacement of normalweight aggregate with LWA.

Program I included LWA mixtures with three replacement levels of LWA-8.9, 11.3, and $13.8 \%$ by aggregate volume (designated as low, medium, and high) —and two mixtures that served as controls. The mixture with the low LWA replacement contained approximately the same aggregate water content as the mixtures in Programs I and II containing limestone coarse aggregate. Program II included two LWA mixtures (an LWA replacement of 8.4\% by aggregate volume) containing Grade 100 slag cement, two mixtures containing limestone coarse aggregate and Grade 100 slag cement, and two mixtures that served as controls. The control mixtures for both programs contained a granite or limestone coarse aggregate combined with river-run pea gravel and sand. In the LWA mixtures, the LWA replaced a portion of the pea gravel.

The mixtures in Program I were proportioned using a water-cement ratio $(w / c)$ of $0.44,540 \mathrm{lb} / \mathrm{yd}^{3}\left(320 \mathrm{~kg} / \mathrm{m}^{3}\right)$ of Type I/II cement, a nominal air content of $8 \%$, and an HRWRA to produce a slump of approximately $3 \mathrm{in}$. $(75 \mathrm{~mm}$ ). The total paste (cement plus water) content was $24.10 \%$ by volume. The mixtures in Program II had similar proportions, except those mixtures contained slag cement at either a 30 or $60 \%$ volume replacement of portland cement. The $w / \mathrm{cm}$ was 0.44 , and the paste content ranged from 24.18 to $24.29 \%$ by volume. The paste contents, which are indicative of those used to produce low-shrinkage mixtures in the field, ${ }^{3,15,19}$ were held within a narrow range to minimize the effect of paste content on drying shrinkage.

The concrete was mixed in a counter-current pan mixer in accordance with ASTM C192/C192M-07. ${ }^{20}$

\section{Free shrinkage and strength}

The free shrinkage tests were performed in accordance with ASTM C157/C157M-08. ${ }^{21}$ Six free shrinkage specimens were prepared for each batch of concrete; three were cured for 7 days and three were cured for 14 days. The specimens were demolded $23.5 \pm 0.5$ hours after casting, immediately wrapped in wet towels, and placed under running water to prevent moisture loss. Initial length readings were taken, and the specimens were placed in lime-saturated water for 6 or 13 days (for a total curing time of 7 or 14 days). After curing, the specimens were dried at $73^{\circ} \pm 3^{\circ} \mathrm{F}\left(23^{\circ} \pm 2^{\circ} \mathrm{C}\right)$ and $50 \% \pm 4 \%$ relative humidity for 1 year. The temperature and humidity varied somewhat during the tests, causing some fluctuations in the free shrinkage readings. The temperature and humidity, however, remained within the limits prescribed by ASTM C157/C157M-08. ${ }^{21}$ Readings were taken daily for the first 30 days, every other day for Days 31 to 90, weekly for Days 91 to 180 , and monthly thereafter.

In addition to the free shrinkage specimens, six $4 \times 8$ in. $(100 \times 200 \mathrm{~mm})$ cylinders were cast for testing in accordance with ASTM C39/C39M-09a. ${ }^{22}$ Three cylinders were cured for 7 days and three were cured for 28 days. The cylinders were demolded $23.5 \pm 0.5$ hours after casting and immediately placed in lime-saturated water for the remainder of the curing period.

\section{EXPERIMENTAL RESULTS AND DISCUSSION Mixture properties}

The properties of the mixtures in Programs I and II are shown in Table 2. The concrete slumps ranged from 2 to $4 \mathrm{in}$. (50 to $100 \mathrm{~mm}$ ) and the air contents ranged from 7.9 to $8.9 \%$, measured in accordance with ASTM C173/C173M-0923 (volumetric method). The unit weights of the mixtures containing only normalweight aggregates were approximately $139 \mathrm{lb} / \mathrm{yd}^{3}$ $\left(2227 \mathrm{~kg} / \mathrm{m}^{3}\right)$, whereas those containing LWA ranged from $130.5 \mathrm{lb} / \mathrm{ft}^{3}\left(2091 \mathrm{~kg} / \mathrm{m}^{3}\right)$ for the LWA-high replacement mixture in Program I to $135.3 \mathrm{lb} / \mathrm{ft}^{3}\left(2168 \mathrm{~kg} / \mathrm{m}^{3}\right)$ for the LWA-30\% slag mixture in Program II. At 7 days, the compressive strengths of the concretes without slag ranged from $2950 \mathrm{psi}(20.3 \mathrm{MPa})$ for the control mixture containing granite coarse aggregate in Program II to $3700 \mathrm{psi}(25.5 \mathrm{MPa})$ for the control mixture containing granite in Program I. At 7 days, the specimens containing slag exhibited strengths between 2690 psi (18.5 MPa) for the LWA-60\% slag mixture in Program II to $3240 \mathrm{psi}$ (22.3 MPa) for the LWA-30\% slag mixture in the same program. The limestone mixtures containing slag exhibited strengths between those for the two LWA slag aggregate mixtures. At 28 days (with one exception), the compressive strengths ranged from 4450 to $4950 \mathrm{psi}$ (30.7 to $34.4 \mathrm{MPa}$ ). 
Table 3-Average free shrinkage, Programs I and II, $\mu \varepsilon^{*}$

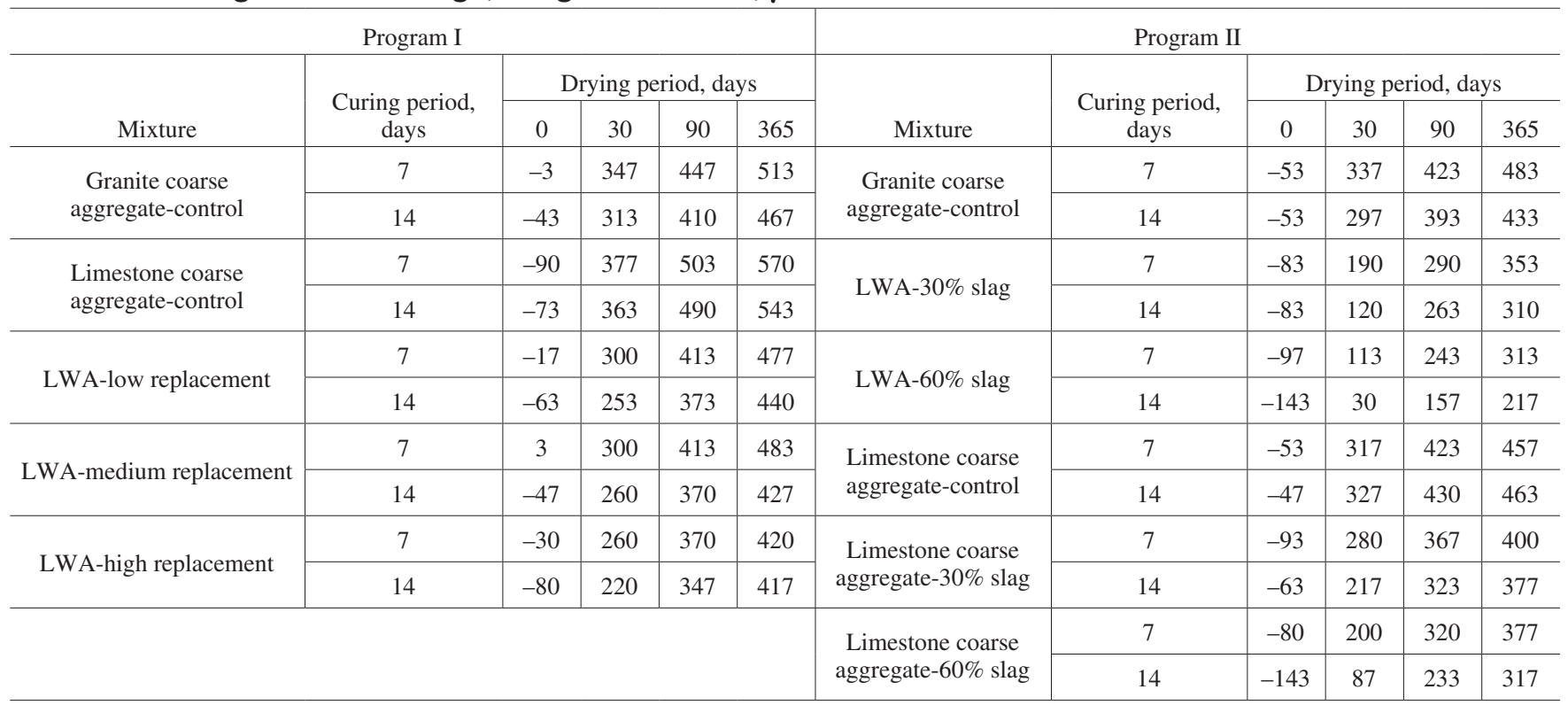

"Values based on length measured upon removal from molds $23.5 \pm 0.5$ hours after casting.

The one exception was the granite control mixture in Program II with a compressive strength of $4140 \mathrm{psi}$ (28.5 MPa). The three highest-strength mixtures contained slag cement with strengths of 4950, 4910, and $4900 \mathrm{psi}$ (34.1, 33.9, and 33.8 MPa) for the LWA-30\%, LWA-60\%, and limestone-30\% mixtures, respectively.

Overall, in the percentages used, the LWA resulted in a small reduction in concrete density and had no appreciable effect on compressive strength.

\section{Free shrinkage}

Program I-Program I was designed to compare the free shrinkage of mixtures containing varying replacement levels of PVS-SD LWA with that of control mixtures containing a low-absorption granite coarse aggregate and a high-absorption limestone coarse aggregate. The average shrinkage strains for the drying periods of $0,30,90$, and 365 days and curing periods of 7 and 14 days are summarized in Table 3. The average free shrinkage is plotted as a function of the drying period for the mixtures in Program I over 30 and 365 days in Fig. 1 and 2, respectively. Shrinkage during the first 30 days is of particular importance for structures such as concrete bridge decks, in which dimensional change is restrained because of the high percentage of the total shrinkage that occurs and the relatively short period available for creep to reduce tensile stresses. In the figures, the mixtures/curing periods are shown in the key in the order of descending shrinkage at the end of 30 or 365 days.

As shown in Table 3 and Fig. 1, increasing the replacement percentage of normalweight aggregate with LWA and increasing the curing period from 7 to 14 days consistently reduces early-age shrinkage. By 30 days, the limestone control mixture, cured for 7 or 14 days, exhibits the highest shrinkage (377 $\mu \varepsilon$ and $363 \mu \varepsilon$, respectively), and the LWA-high replacement mixture cured for 14 days exhibits the lowest shrinkage $(220 \mu \varepsilon)$. It should be noted that the limestone control mixture and LWA-low replacement mixture have nearly the same internal water content (45 and $46 \mathrm{lb} / \mathrm{yd}^{3}$ [26.7 and $27.3 \mathrm{~kg} / \mathrm{m}^{3}$ ], respectively), but the LWA is much more effective in reducing free

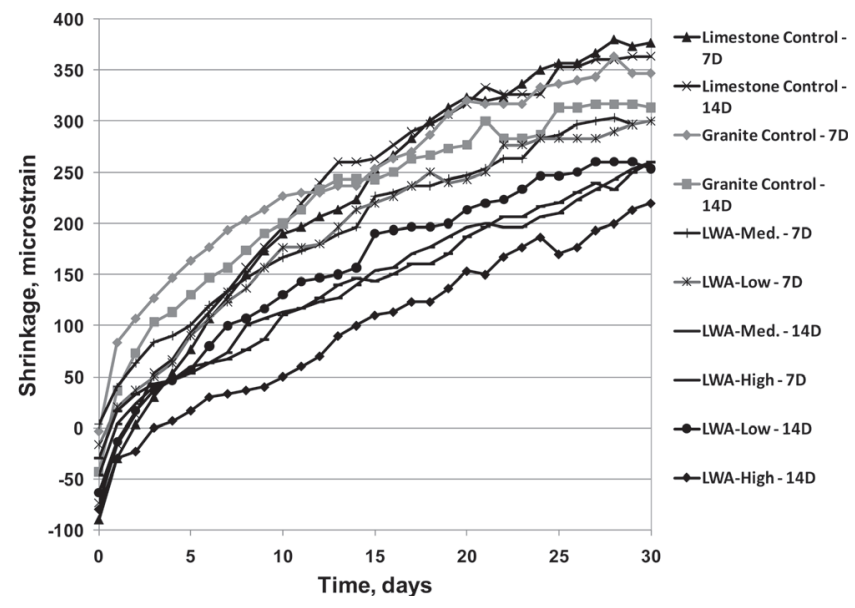

Fig. 1-Free shrinkage versus drying time through 30 days for concrete in Program I.

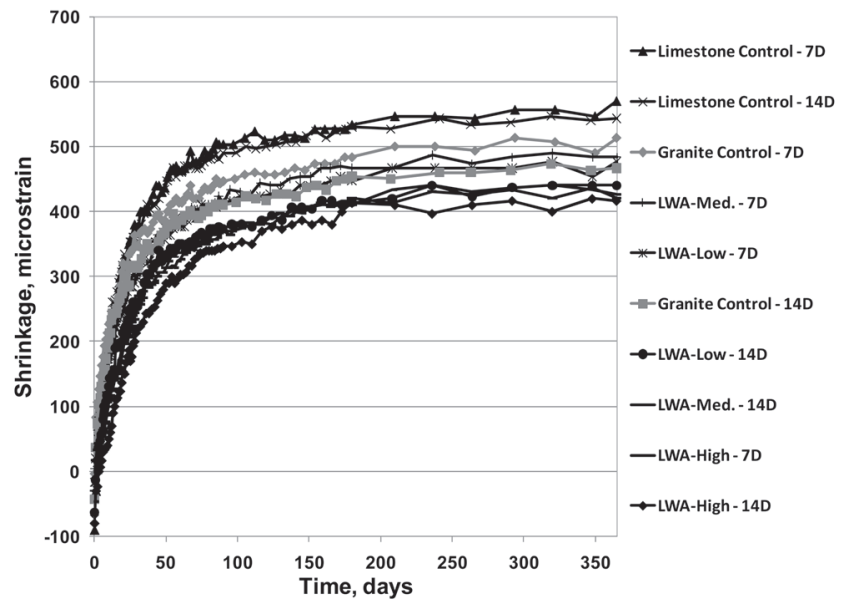

Fig. 2-Free shrinkage versus drying time through 365 days for concrete in Program I. 


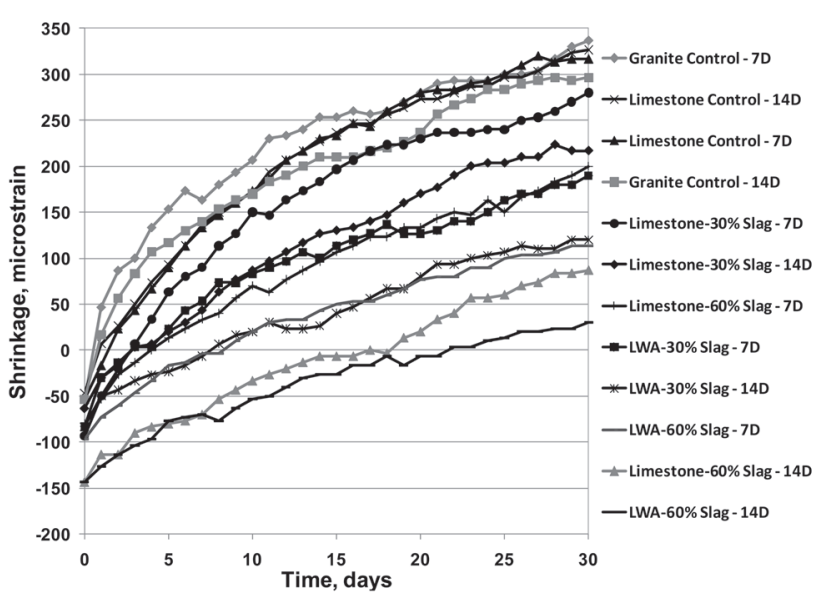

Fig. 3-Free shrinkage versus drying time through 30 days for concrete in Program II.

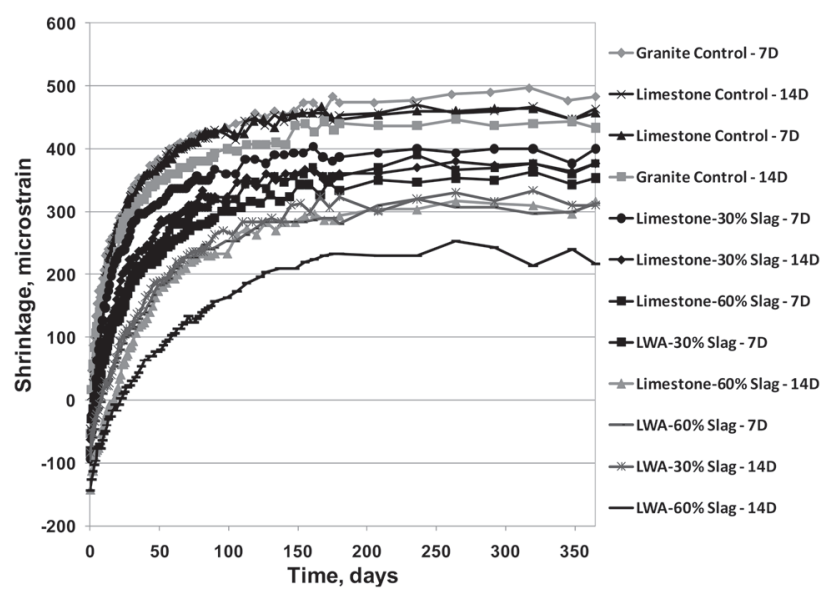

Fig. 4-Free shrinkage versus drying time through 365 days for concrete in Program II.

shrinkage (363 $\mu \varepsilon$ and $253 \mu \varepsilon$, respectively, after curing for 14 days). The low and medium replacement LWA mixtures exhibit similar values of shrinkage for the respective curing periods of 7 and 14 days, with the 14-day curing period producing 40 to $50 \mu \varepsilon$ less shrinkage than the 7-day curing period. The granite control mixture exhibits lower shrinkage than the limestone control mixture by $30 \mu \varepsilon$ and $50 \mu \varepsilon$ for curing periods of 7 and 14 days, respectively.

For a drying period of 365 days (Table 3 and Fig. 2), increasing the level of LWA replacement and increasing the curing period from 7 to 14 days continues to result in lower shrinkage, although the order of descending shrinkage changes to some extent. In addition, the reduction in shrinkage strain resulting from the increased curing period decreases compared to the reduction observed at 30 days, except for the granite control mixture, for which the specimens cured for 14 days exhibit $46 \mu \varepsilon$ lower shrinkage at 365 days compared to $34 \mu \varepsilon$ at 30 days. Overall, the LWA-high replacement mixture cured for 14 days continues to exhibit the lowest shrinkage at 365 days $(417 \mu \varepsilon)$, whereas the limestone control mixture cured for 7 days continues to exhibit the highest shrinkage $(570 \mu \varepsilon)$.

The lower shrinkage strain exhibited by the granite control mixture compared to the limestone control mixture is likely

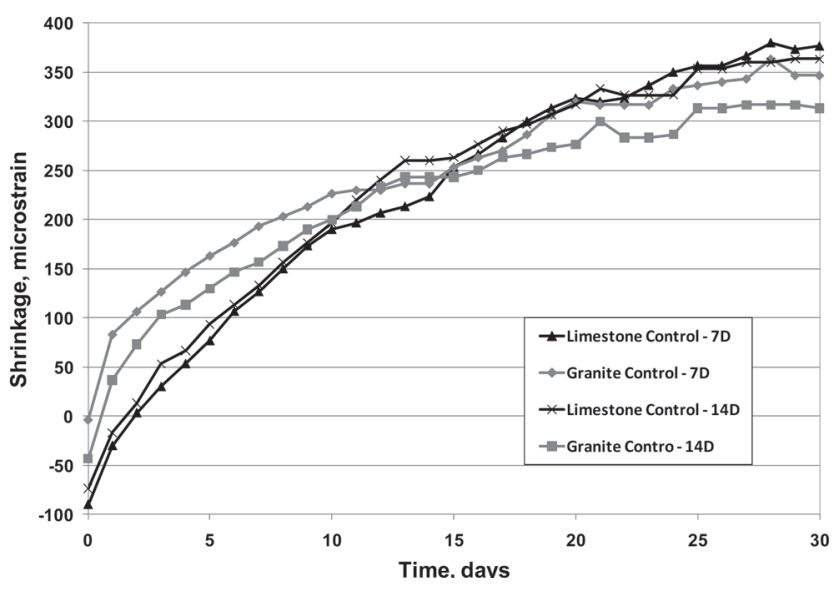

Fig. 5-Free shrinkage versus drying time through 30 days for control mixtures in Program I.

due to the greater restraint provided by the higher modulus of elasticity of the granite.

Program II-Program II was designed to compare mixtures containing 30 and $60 \%$ replacements of portland cement with slag cement, with internal curing provided by either LWA or porous limestone. The average values of free shrinkage are shown, along with those from Program I, in Table 3 and Fig. 3 and 4. Figures 3 and 4 cover the drying periods through 30 days and 365 days, respectively. At 30 days, an increase in slag replacement and, with one exception (the limestone control mixture), an increase in curing period resulted in a decrease in shrinkage. The lowest shrinkage is exhibited by the LWA-60\% slag mixture, with a shrinkage of only $30 \mu \varepsilon$, followed by the limestone- $60 \%$ slag mixture, with a shrinkage of just $87 \mu \varepsilon$ (both were cured for 14 days). The highest shrinkage is exhibited by the granite control mixture cured for 7 days, with a shrinkage of $337 \mu \varepsilon$. The LWA is more effective than the limestone in providing internal curing, at least in part because of the greater quantity of moisture held within the aggregate (approximately 60 versus $45 \mathrm{lb} / \mathrm{yd}^{3}$ [36.6 versus $\left.26.7 \mathrm{~kg} / \mathrm{m}^{3}\right]$ ). The shrinkage strain of $30 \mu \varepsilon$ exhibited by the LWA-60\% slag mixture appears to be abnormally low.

At 365 days (Table 3 and Fig. 4), the LWA-60\% slag mixture cured for 14 days continues to exhibit the lowest shrinkage $(217 \mu \varepsilon)$, followed by the same mixture cured for 7 days $(313 \mu \varepsilon)$. The granite control mixture cured for 7 days exhibits the highest shrinkage $(483 \mu \varepsilon)$, followed by the limestone control mixtures cured for 14 and 7 days (463 $\mu \varepsilon$ and $457 \mu \varepsilon$, respectively) and the granite control mixture cured for 14 days $(433 \mu \varepsilon)$. Overall, increasing the percentage of slag replacement, using LWA, and curing for a longer period (with a single exception) results in reduced shrinkage (the exception: the limestone control mixture cured for 14 days exhibited slightly more shrinkage than the same mixture cured for 7 days at nearly all ages, as shown in Table 3).

Figures 5 and 6 illustrate the difference in very early-age shrinkage between the limestone and granite control mixtures for Programs I and II, respectively. The internal curing provided by the water in the pores of the limestone coarse aggregate, coupled with the ability of the water within the limestone to replace water lost due to evaporation, results in reduced shrinkage for approximately 12 days for the Program I specimens and for 10 to 25 days for the Program II 


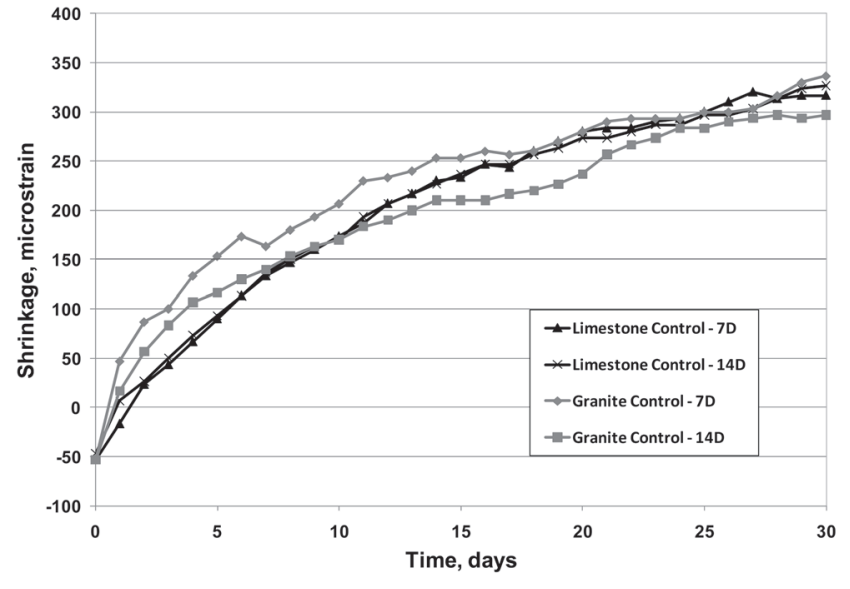

Fig. 6-Free shrinkage versus drying time through 30 days for control mixtures in Program II.

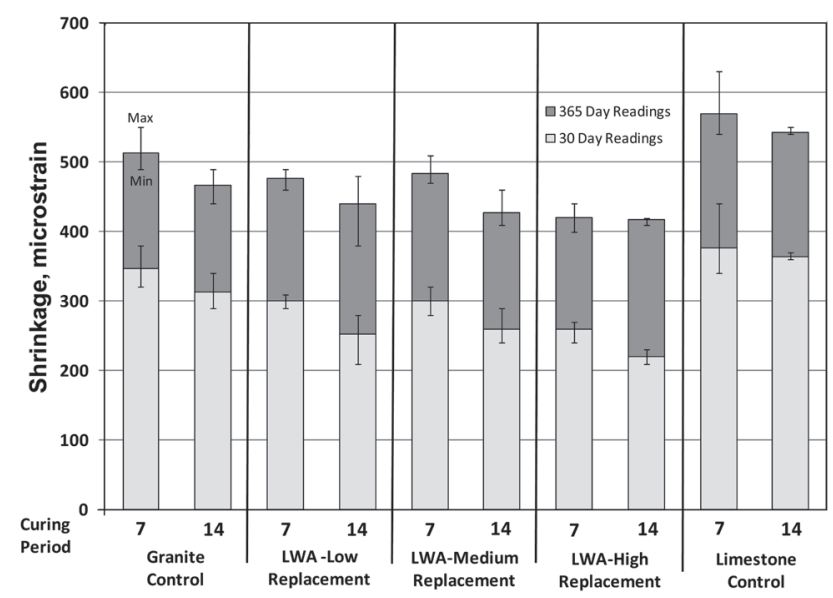

Fig. 7-Free shrinkage at 30 and 365 days for curing periods of 7 and 14 days for mixtures in Program I.

specimens, depending on the curing period. Afterward, the effect of the higher stiffness of the granite compared to the limestone in restraining shrinkage is apparent.

Figures 7 and 8 illustrate the degree to which using LWA as an internal curing agent and increasing the curing period resulted in reduced shrinkage in this study. In addition to the average values of free shrinkage, the figures also show the maximum and minimum values for the three specimens used for each parameter. For Program I (Fig. 7), the impact of both factors on lowering shrinkage is apparent in all cases at 30 and 365 days. This trend is consistent even when the maximum and minimum values shown in the graphs are considered. For Program II (Fig. 8), the observations are similar, except for the effect of the curing period on the limestone control mixture. Figure 8 also illustrates the major reductions provided by slag cement when used in combination with aggregates that provide internal curing, especially LWA. Thus, internal curing, longer curing, and slag cement, used in conjunction with internal curing, will result in reduced shrinkage. In this study, the difference is substantial. The maximum and minimum values support the trends, except the maximum value for the LWA-60\% slag specimens with 14 days of curing and 30 days of drying overlaps with the minimum value at 365 days of drying. This is caused by the free shrinkage value of one specimen

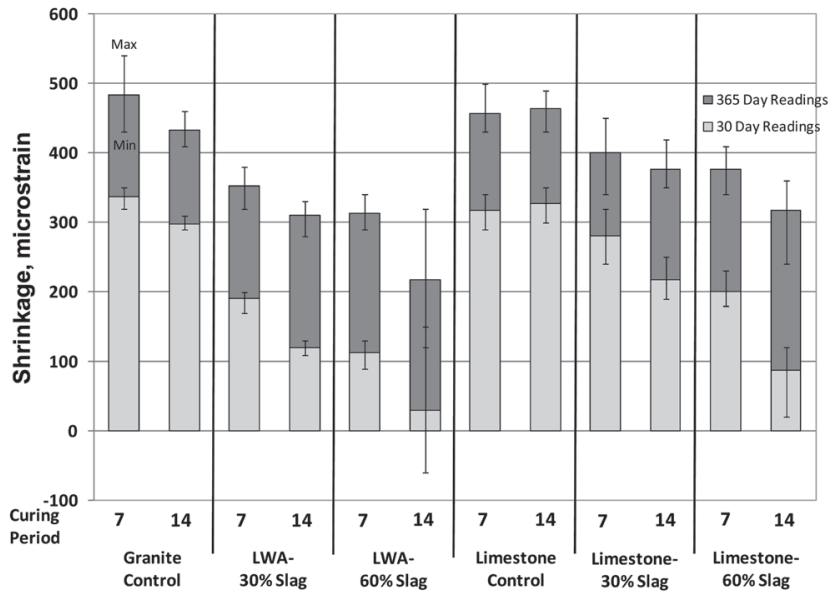

Fig. 8-Free shrinkage at 30 and 365 days for curing periods of 7 and 14 days for mixtures in Program II.

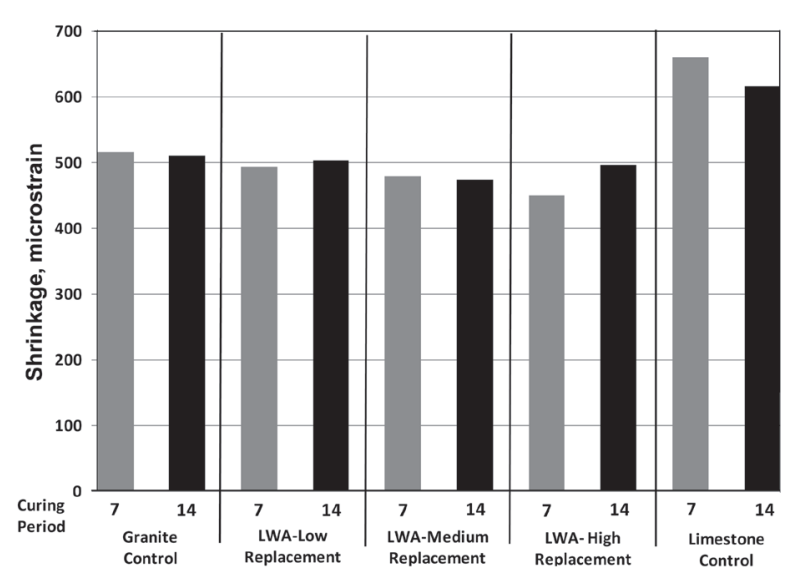

Fig. 9-Free shrinkage at 365 days based on total length change after curing for curing periods of 7 and 14 days for mixtures in Program $I$.

at 30 days of drying being much higher than the other two free shrinkage values.

As shown in Fig. 1 through 4, the specimens exhibit various amounts of swelling (negative shrinkage) at the end of the curing period. In this study, increasing the curing period from 7 to 14 days resulted in higher swelling for seven out of the 13 mixtures, identical or nearly identical swelling for five mixtures, and lower swelling for one mixture (limestone-30\% slag). An increase in swelling is potentially beneficial in the case of concrete that is restrained, such as in bridge decks, because it places the concrete in compression.

Figures 9 and 10 show the average values of free shrinkage based on the total length change after curing through 365 days, thus discounting the effect of swelling. These figures illustrate that with one exception (the LWA-high replacement mixture from Program I), reduced shrinkage obtained through the use of an increased curing period, the use of LWA for internal curing, or the use of slag cement is maintained or improved over 365 days, independent of swelling.

\section{SUMMARY AND CONCLUSIONS}

The effectiveness of prewetted, vacuum-saturated lightweight aggregate (PVS LWA) as an internal curing agent to reduce concrete shrinkage is evaluated using 11 concrete mixtures that cover the effects of LWA replacement levels 


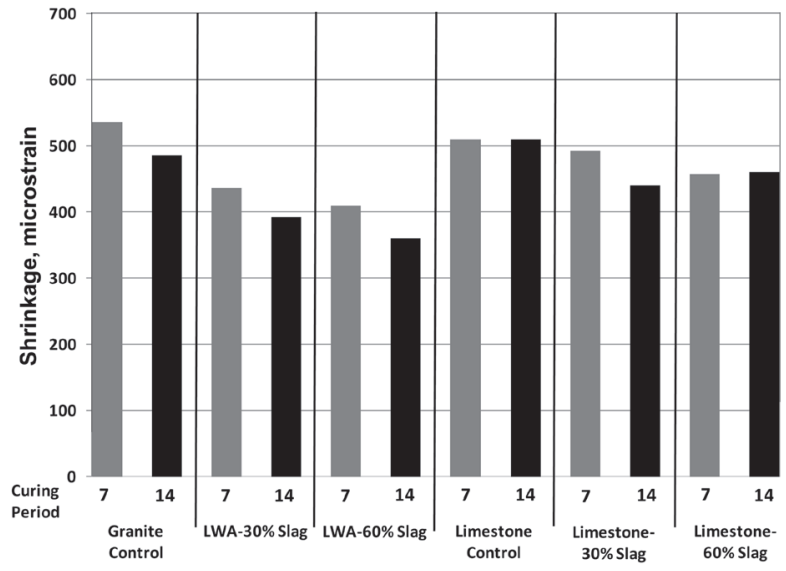

Fig. 10 - Free shrinkage at 365 days based on total length change after curing for curing periods of 7 and 14 days for mixtures in Program II.

ranging from 8.9 to $13.8 \%$ based on volume and performance when used in conjunction with Grade 100 slag cement. Comparisons are made with mixtures containing a low-absorption (0.71 to $0.76 \%$ ) granite coarse aggregate and a high-absorption (3.07\%) limestone coarse aggregate. All mixtures have a $w / \mathrm{cm}$ of 0.44 , a cement paste content of approximately $24.1 \%$, and an air content of approximately $8 \%$. Seven- and 14-day curing periods are evaluated and compressive strengths are compared at 7 and 28 days.

The following conclusions are based on the results and evaluations presented in this paper:

1. At the percentages used in this study to provide internal curing, PVS LWA results in a small reduction in concrete densities and has no appreciable effect on concrete compressive strength at 7 or 28 days.

2. When used as an internal curing agent, PVS LWA substantially decreases concrete shrinkage for periods of up to 365 days.

3. Increasing the curing period from 7 to 14 days reduces concrete shrinkage.

4. When used in conjunction with either porous limestone or PVS LWA to provide internal curing, 30 and $60 \%$ volume replacements of portland cement by slag cement results in reduced shrinkage.

5. Of the two porous aggregates tested, the PVS LWA is more effective than the porous limestone at reducing shrinkage in both the short and long term when used in conjunction with slag cement.

\section{ACKNOWLEDGMENTS}

Funding for this research was provided by the Kansas Department of Transportation, serving as the lead agency for the "Construction of CrackFree Bridge Decks" Transportation Pooled Fund Study under Projects No. TPF-5(051) and TPF-5(174), along with the Federal Highway Administration (FHWA) of the U.S. Department of Transportation and the Departments of Transportation of Colorado, Delaware, Idaho, Indiana, Michigan, Minnesota, Mississippi, Missouri, Montana, New Hampshire, New York, North Dakota, Ohio, Oklahoma, South Dakota, Texas, Wisconsin, and Wyoming, and the University of Kansas Transportation Research Institute. LRM Industries; Buildex, Inc.; BASF Construction Chemicals; Holcim US; Fordyce Concrete; Grace Construction Products; Ash Grove Cement; and Lafarge North America provided concrete materials.

\section{REFERENCES}

1. Darwin, D.; Browning, J.; and Lindquist, W. D., "Control of Cracking in Bridge Decks: Observations from the Field," Cement, Concrete and Aggregates, V. 26, No. 2, Dec. 2004, pp. 148-154.

2. Lindquist, W. D.; Darwin, D.; Browning, J.; and Miller, G. G., "Effect of Cracking on Chloride Content in Concrete Bridge Decks," ACI Materials Journal, V. 103, No. 6, Nov.-Dec. 2006, pp. 467-473.

3. Darwin, D.; Browning, J.; Lindquist, W.; McLeod, H. A. K.; Yuan, J.; Toledo, M.; and Reynolds, D., "Low-Cracking, High-Performance Concrete Bridge Decks-Case Studies Over the First 6 Years," Transportation Research Record: Journal of the Transportation Research Board, No. 2202, 2010, pp. 61-69.

4. Hobbs, D. W., "Influence of Aggregate Restraint on the Shrinkage of Concrete," ACI Journal, Proceedings V. 71, No. 9, Sept. 1974, pp. 445-450.

5. Zhutovsky, S.; Kovler, K.; and Bentur, A., "Efficiency of Lightweight Aggregates for Internal Curing of High Strength Concrete to Eliminate Autogenous Shrinkage," Materials and Structures, V. 35, 2002, pp. 97-101.

6. Philleo, R. E., "Concrete Science and Reality," Materials Science of Concrete II, J. P. Skalny and S. Mindess, eds., American Ceramic Society, Westerville, OH, 1991, pp. 1-8.

7. Bentz, D. P., and Snyder, K. A., "Protected Paste Volume in Concrete: Extension to Internal Curing Using Saturated Lightweight Fine Aggregate," Cement and Concrete Research, V. 29, No. 11, Nov. 1999, pp. 1863-1867.

8. Bentur, A.; Igarashi, S.-I.; and Kovler, K., "Prevention of Autogenous Shrinkage in High-Strength Concrete by Internal Curing Using Wet Lightweight Aggregates," Cement and Concrete Research, V. 31, No. 11, Nov. 2001, pp. 1587-1591.

9. Bentz, D. P.; Lura, P.; and Roberts, J. W., "Mixture Proportioning for Internal Curing," Concrete International, V. 27, No. 2, Feb. 2005, pp. 35-40.

10. Ye, J. et al., "Effect of Pre-Wetted Lightweight Aggregate on Internal Relative Humidity and Autogenous Shrinkage of Concrete," Journal of Wuhan University of Technology-Materials Science Edition, V. 21, No. 1, 2006, pp. 134-137.

11. Hammer, T. A.; Bjontegaard, O.; and Sellevold, E. G., " Internal Curing-Role of Absorbed Water in Aggregates," High-Performance Structural Lightweight Concrete, SP-218, J. Ries and T. Holm, eds., American Concrete Institute, Farmington Hills, MI, 2004, pp. 131-142.

12. Jardine, D. J., and Wolhuter, C. W., "Some Properties of High-Slag Concrete," Civil Engineer in South Africa, V. 19, No. 11, 1977, pp. 249-251.

13. Tazawa, E.; Yonekura, A.; and Tanaka, S., "Drying Shrinkage and Creep of Concrete Containing Granulated Blast Furnace Slag," Fly Ash, Silica Fume, Slag and Natural Pozzolans in Concrete, SP-114, V. M. Malhotra, ed., American Concrete Institute, Farmington Hills, MI, 1989, pp. 1325-1343.

14. Darwin, D.; Lindquist, W. D.; McLeod, H. A. K.; and Browning, J., "Mineral Admixtures, Curing, and Concrete Shrinkage-An Update," Concrete Technology, V. 1, No. 1, Oct. 2007, pp. 56-65.

15. Lindquist, W. D.; Darwin, D.; and Browning, J., "Development and Construction of Low-Cracking High-Performance Concrete (LC-HPC) Bridge Decks: Free Shrinkage, Mixture Optimization, and Concrete Production," SM Report No. 92, University of Kansas Center for Research, Lawrence, KS, Nov. 2008, 504 pp.

16. Powers, T. C., "Causes and Control of Volume Change," Journal of Portland Cement Association Research and Development Laboratories, V. 1, Jan. 1959, pp. 29-39.

17. Reynolds, D.; Browning, J.; and Darwin, D., "Lightweight Aggregates as an Internal Curing Agent for Low-Cracking High-Performance Concrete," SM Report No. 97, University of Kansas Center for Research, Lawrence, KS, Dec. 2009, 151 pp.

18. ACI Committee 211, "Standard Practice for Selecting Proportions for Structural Lightweight Concrete (ACI 211.2-98) (Reapproved 2004)," American Concrete Institute, Farmington Hills, MI, 1998, 20 pp.

19. McLeod, H. A. K.; Darwin, D.; and Browning, J., "Development and Construction of Low-Cracking High-Performance Concrete (LC-HPC) Bridge Decks: Construction Methods, Specifications, and Resistance to Chloride Ion Penetration," SM Report No. 94, University of Kansas Center for Research, Lawrence, KS, Sept. 2009, 815 pp.

20. ASTM C192/C192M-07, "Standard Practice for Making and Curing Concrete Test Specimens in the Laboratory," ASTM International, West Conshohocken, PA, 2007, 8 pp.

21. ASTM C157/C157M-08, "Standard Test Method for Length Change of Hardened Hydraulic-Cement Mortar and Concrete," ASTM International, West Conshohocken, PA, 2008, 7 pp.

22. ASTM C39/C39M-09a, "Standard Test Method for Compressive Strength of Cylindrical Concrete Specimens," ASTM International, West Conshohocken, PA, 2009, 7 pp.

23. ASTM C173/C173M-09, "Standard Test Method for Air Content of Freshly Mixed Concrete by the Volumetric Method," ASTM International, West Conshohocken, PA, 2009, 8 pp. 